\title{
The Burden of Diverticular Disease and Its Complications: West versus East
}

\author{
Hiroyuki Imaeda ${ }^{\text {a }}$ Toshifumi Hibi $^{\text {b }}$

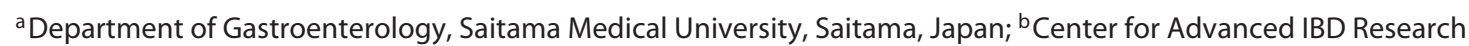 \\ and Treatment, Kitasato University Kitasato Institute Hospital, Tokyo, Japan
}

\section{Keywords}

Diverticular bleeding · Diverticulosis · Diverticulitis · East · West

\begin{abstract}
Background: Colonic diverticulosis is prevalent and increasing not only in Western but also in Asian countries. Diverticulosis can be complicated by diverticulitis and diverticular bleeding. Diverticular disease is a burdensome digestive disease, because it is a major cause of hospital admissions and is associated with significant health-care costs. Summary: The incidence of diverticulosis increases with age. Most cases of diverticulosis in Western countries involve the left side of the colon, while diverticulosis is predominantly present on the right side of the colon in Asian countries. The incidence of diverticulitis also increases with age. Diverticulitis is predominantly located on the left side of the colon in Western countries, while it is predominantly located on the right side of the colon in Asian countries. The overall complication rate is higher in left-sided than in right-sided diverticulitis. The incidence of diverticular bleeding also increases with age. The right colon is the source of diverticular bleeding in more than $50 \%$ of patients in Western countries. In
\end{abstract}

\section{KARGER}

(C) 2018 S. Karger AG, Basel

E-Mail karger@karger.com

www.karger.com/iid
Asian countries, age greater than 70 years and both-sided diverticulosis increase the bleeding risk. Key Messages: In Western countries, diverticulosis and diverticulitis are predominantly located on the left side of the colon, whereas they are predominantly present on the right side of the colon in Asian countries. Diverticular bleeding is predominantly located on the right side in Western countries, and both-sided diverticulosis increases the risk of bleeding in Asian countries. Diverticular disease with complications requires admission and operation; moreover, it recurs frequently. Therefore, diverticular disease is associated with a significant economic burden in terms of health-care costs and resource utilization.

(c) 2018 S. Karger AG, Basel

\section{Introduction}

The prevalence of colonic diverticulosis is increasing in Western and Asian countries [1-3]. Diverticular disease is defined as clinically significant and symptomatic diverticulosis complicated by diverticulitis, diverticular bleeding, segmental colitis associated with diverticula, or symptomatic uncomplicated diverticular disease; these 
Table 1. Differences in diverticular disease between Western and Asian countries

\begin{tabular}{lll}
\hline & Western countries & Asian countries \\
\hline Prevalence of diverticulosis & $5-45 \%$ & $13-25 \%$ \\
Location of diverticulosis & $\mathrm{R}<\mathrm{L}$ & $\mathrm{R}>\mathrm{L}$, both \\
Location of diverticulitis & $\mathrm{R}<\mathrm{L}$ & $\mathrm{R}>\mathrm{L}$ \\
Location of complication of diverticulitis & $\mathrm{R}<\mathrm{L}$ & $\mathrm{R}<\mathrm{L}$ \\
Mortality rate of diverticulitis & $0.96-2.2 \%$ & $0.63 \%$ \\
$\quad$ Non-Asian & $2.2 \%$ & \\
Asian & $4.2 \%$ & both \\
Location of diverticular bleeding & $\mathrm{R}>\mathrm{L}$ & $0.7-4.1 \%$ \\
Mortality of diverticular bleeding & $1.1-4.1 \%$ & \\
\hline
\end{tabular}

$\mathrm{R}$, right-sided colon; L, left-sided colon; both, both-sided colon.

are the so-called complications of colonic diverticulosis. The incidence of diverticular disease is increasing over time in both Western and Asian countries [3]. Diverticular disease is responsible for a high number of gastrointestinal admissions and clinical visits. Moreover, it often recurs. Therefore, it is associated with a significant economic burden in terms of health-care costs, hospitalization, and resource utilization not only in Western but also in Asian countries. Furthermore, the incidence of diverticular disease appears to be increasing with aging $[4,5]$. However, the prevalence of diverticulosis, diverticulitis, and diverticular bleeding in Western countries is different from that in Asian countries.

The distribution and clinical characteristics of colonic diverticulosis, diverticulitis, and diverticular bleeding, in addition to the differences in presentation between Western and Asian countries, are reviewed in this article.

\section{Diverticulosis}

Western countries have prevalence rates of $5-45 \%$ for diverticulosis, depending on the method of diagnosis and the age of the population (Table 1) [6,7]. Prior studies have shown an increase in the prevalence of diverticulosis from the mid-1990s through the early part of the current century. This increase has been most notable among young individuals [1]. Approximately $95 \%$ of patients with diverticulosis had diverticula in the sigmoid colon [8]. Diverticula were located only in the sigmoid colon in $65 \%$ of patients and in other parts of the colon, along with the sigmoid colon, in $24 \%$ of patients; they were equally distributed throughout the colon in $7 \%$ of patients and were located in a segment proximal to the sigmoid colon in $4 \%$ of patients. In one prospective study of 624 individuals undergoing screening colonoscopy in the United States, 260 (42\%) had colonic diverticulosis [9]. Participants with diverticula were more likely to be older and male; moreover, they had a higher body mass index and waist circumference than those without diverticula. The prevalence of diverticulosis was 35\% in those younger than 50 years, $40 \%$ in individuals $50-59$ years old, and $58 \%$ in those older than 60 years [9]. The prevalence of diverticulosis according to the Clinical Outcomes Research Initiative National Endoscopy Database was 33\% in individuals $50-59$ years old and $71 \%$ in those older than 80 years [10].

The distribution of diverticula differs significantly according to race. Among white persons, $75 \%$ of diverticula were located in the sigmoid colon, $11 \%$ in the descending colon or splenic flexure, $6 \%$ in the transverse colon, and $8 \%$ in the ascending colon or hepatic flexure [9]. In black persons, $64 \%$ of diverticula were located in the sigmoid colon, $8 \%$ in the descending colon or splenic flexure, $7 \%$ in the transverse colon, and $20 \%$ in the ascending colon or hepatic flexure. The distribution of the diverticula in the ascending colon or hepatic flexure was higher in blacks than in whites [9]. This finding supports a possible genetic contribution to the development of diverticulosis, but this distribution may also be caused by differences in health behaviors or environmental factors.

Similarly, a British study of 1,000 barium enemas in patients with gastrointestinal symptoms found that black Africans were more likely to have diverticulosis that involved the proximal colon than white persons [11]. It was found that Asians and blacks, including those from the Caribbean, were protected against left-sided diverticular disease compared to whites, with the odds ratio of left-
Imaeda/Hibi 
sided diverticular disease being 0.23 (95\% CI $0.10-0.53$, $p<0.001)$ and 0.25 (95\% CI $0.14-0.43, p<0.001)$ of that in whites, respectively. In right-sided diverticular disease, a 1 -year increase in age increased the odds by $4 \%(95 \% \mathrm{CI}$ $2-6, p<0.001)$. Women were 0.60 times (95\% CI $0.40-$ $0.90, p=0.01)$ less likely than men, while black Africans were 3.51 times $(95 \%$ CI $1.70-7.24, p<0.001)$ more likely than whites, to have right-sided diverticular disease.

The prevalence of diverticulosis has been estimated prospectively in several colonoscopy-based studies in Asia. The prevalence of diverticulosis in Lebanon was similar to that in the United States [12]; that is, the rate was 33\% (mean age: 61 years), and most subjects had distal diverticulosis. However, other studies from the Middle East suggest a much lower prevalence. The prevalence of diverticulosis is between 13 and 25\% in the Far East, and diverticulosis is predominantly right-sided (Table 1).

Additionally, the prevalence of diverticulosis was $12 \%$ in Korea (mean age: 51 years) [13] and 14\% in Taiwan (mean age: 53 years) [14]. Barium studies in Japan have shown a significant increase in the prevalence of diverticulosis in the late 1900s, from $2.1 \%$ in 1967 and $7.8 \%$ in 1983 to $28 \%$ in 1997 ; the increase may be associated with the adoption of a Western lifestyle [15-18]. Yamamichi et al. [2] reported that the incidence of diverticulosis was $13.0 \%$ from 1990 to 2000 and $23.9 \%$ from 2001 to 2010 : the latter value was much higher than the former in all age groups and in both sexes. The incidence of left-sided diverticular disease has markedly increased with age but has not significantly changed over time. In Korea, $15 \%$ of patients with colonic diverticulosis had distal diverticula [13], whereas half of the Japanese and Taiwanese populations with colonic diverticulosis had distal diverticula [14, 15].

Increasing age might be a risk factor for colonic diverticula across all of these populations; therefore, diverticula are evidently acquired in these populations and are not congenital [9]. Nagata et al. [3] reported that the proportion of colonic diverticulosis increased significantly from $66.0 \%$ in 2003 to $70.1 \%$ in 2011 and was affecting an increased number of patients aged 60 years and older. Japan has reported an increase in the prevalence of rightsided diverticulosis similar to the increase in left-sided diverticula seen in Westernized countries [19]. The frequency in patients with the right-sided type was $9.7 \%$, which was 5 times greater than that of patients with the left-sided type; however, the frequency of both types increases with advancing years. The left-sided type increased in frequency with increasing age up to the eighth decade and showed no difference in numbers between men and women, whereas the right-sided type was more common in younger people and more predominant in men, with a peak in the seventh decade. The changing frequency of the bilateral type, with respect to both year and age, was similar to that of the left-sided type. In Asian countries, right-sided diverticulosis is thought to be of congenital origin, and diverticula developing subsequently on the left may extend into the bilateral colon [12, 17].

\section{Diverticulitis}

Diverticulitis (Fig. 1) may be acute or chronic and uncomplicated or complicated by a diverticular abscess, fistula, bowel obstruction, or free perforation. Approximately $4-15 \%$ of patients with diverticulosis develop diverticulitis $[1,20,21]$. A nationwide inpatient study of hospitalizations in the United States showed an increase in admissions for acute diverticulitis by $26 \%$ from 1998 to 2005 [22]. Moreover, the prevalence of hospitalizations for diverticulitis peaked in 2008 (74.1 of 100,000 patients in $2000,96.0$ of 100,000 patients in 2008 , and 91.9 of 100,000 patients in 2010 , respectively). Over the past 10 years, the prevalence of hospitalizations for diverticulitis has increased and then plateaued [1].

In Western countries, acute diverticulitis is predominantly left-sided, with right-sided diverticulitis being present in only $1.5 \%$ of patients (Table 1) [23]. In a retrospective cohort of patients in the United States with acute diverticulitis, $72 \%$ had the disease in the sigmoid colon, $33 \%$ in the descending colon, $3 \%$ in the transverse colon, and $5 \%$ in the ascending colon. The prevalence of diverticulitis was highest in whites (75.5 of 100,000 patients in 2010) [1].

The incidence of diverticulitis increases with age. The mean age at admission for acute diverticulitis is 63 years [24]. While the incidence of acute diverticulitis is lower in younger individuals, approximately $16 \%$ of admissions for acute diverticulitis occur among patients aged less than 45 years [4].

The prevalence of diverticulitis is higher in women than in men [1]. Although a male preponderance was noted in early series, subsequent studies have suggested either an equal distribution between the sexes or a female preponderance [25]. Under the age of 50 years, the prevalence of diverticulitis is more common in men; there is a slight female preponderance present between the ages of 50 and 70 years and a marked female preponderance over the age of 70 years [26-28]. 

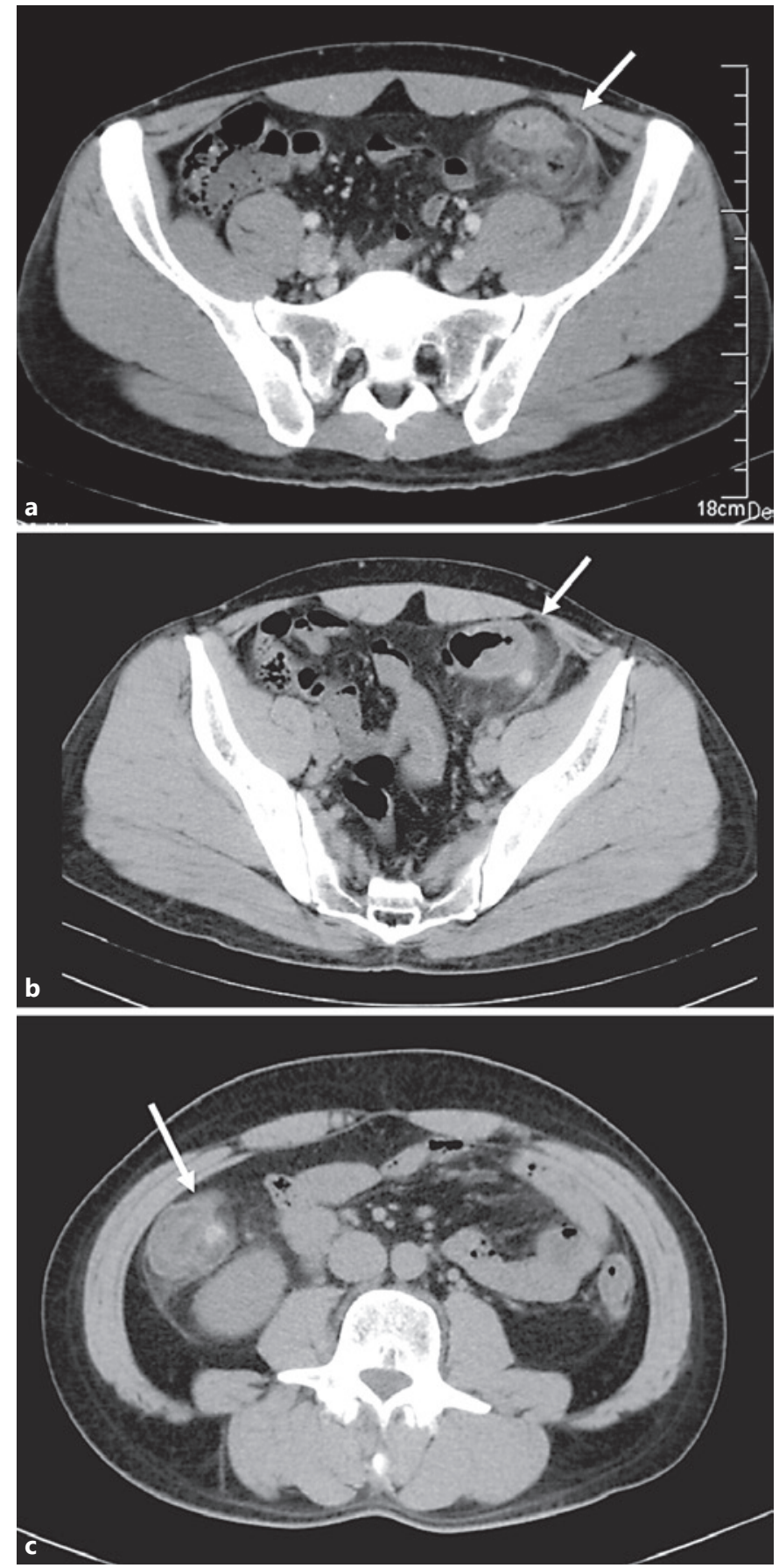

Fig. 1. a A 41-year-old Japanese man with diverticulitis in the sigmoid colon. A computed tomography (CT) scan shows a diverticulum with a thick wall and mild induration of the perisigmoid fat, as well as thickening of the sigmoid mesocolon. $\mathbf{b}$ The same man with recurrence of diverticulitis in the sigmoid colon 2 years later. A CT scan shows a diverticulum with a thick wall and mild induration of the perisigmoid fat, as well as thickening of the sigmoid mesocolon. c The same man with recurrence of diverticulitis in the ascending colon 4 years later. A CT scan shows a diverticulum with a thick wall and mild induration of the periascending fat, as well as thickening of the ascending mesocolon.
Approximately 25\% of patients with acute diverticulitis have associated acute or chronic complications [29]. Diverticular abscesses occur in approximately $17 \%$ of patients hospitalized with acute diverticulitis [30, 31]. Intestinal obstruction can occur because of luminal narrowing due to inflammation or compression from a diverticular abscess. Inflammation from acute diverticulitis may result in the formation of a fistula to the adjacent viscera, especially the bladder [32]. Perforation with generalized peritonitis may result from rupture of a diverticular abscess into the peritoneal cavity or from free rupture of an inflamed diverticulum. Although only $1-2 \%$ of patients with acute diverticulitis have a perforation with purulent or fecal peritonitis, mortality rates approach $20 \%[33,34]$.

In contrast with Western countries, right-sided diverticulitis has a higher incidence in Asian populations (Table 1) [35-39]. In Singapore, Wong et al. [35] reported that $38 \%$ of diverticulitis was on the right side and $49 \%$ was on the left side of the colon. In Japan and Korea, diverticulitis was more common on the right side of the colon [36-39]. Kim et al. [36] reported that diverticulitis occurred on the right side of the colon in $53(76 \%)$ out of 70 cases and on the left side of the colon in 17 cases (24\%). The mean age of patients with right-sided diverticulitis was significantly lower than that of patients with left-sided diverticulitis. However, the overall complication rate was higher in left-sided than in right-sided diverticulitis. Oh et al. [37] reported that diverticulitis, which was treated surgically, occurred on the right side of the colon in 31 cases $(46 \%)$ and on the left side of the colon in 37 cases (54\%). The proportion of left-sided disease cases was significantly higher than that in previous studies from 1994 and 2001 ( 27.5 vs. $48.1 \%$ ). Patients with right-sided disease were significantly younger (50.9 vs. 64.0 years). Furthermore, left-sided disease was significantly associated with a higher incidence of complicated diverticulitis (89.2 vs. $57.5 \%$ ), combined resection of the small intestine or bladder due to extensive inflammation (21.6 vs. $5.0 \%)$, operative complications (51.4 vs. $27.5 \%$ ), and in-hospital mortality ( 10.8 vs. $0 \%)$, along with a longer postoperative hospitalization duration ( $21.3 \pm 10.2$ vs. $10.6 \pm 8.1$ days). Manabe et al. [38] reported the results of a Japanese multicenter study, which showed that although diverticulitis more frequently affected the right colon (70.1\%) among 1,112 patients, diverticulitis of the left colon was significantly more frequent $(61.0 \%)$ in elderly patients.

Schneider et al. [39] reported that the mortality rate in 310,983 emergency department visits for primary diverticulitis was $0.96 \%$, based on the 2010 Nationwide Emergency Department Sample in the United States. Choi et 


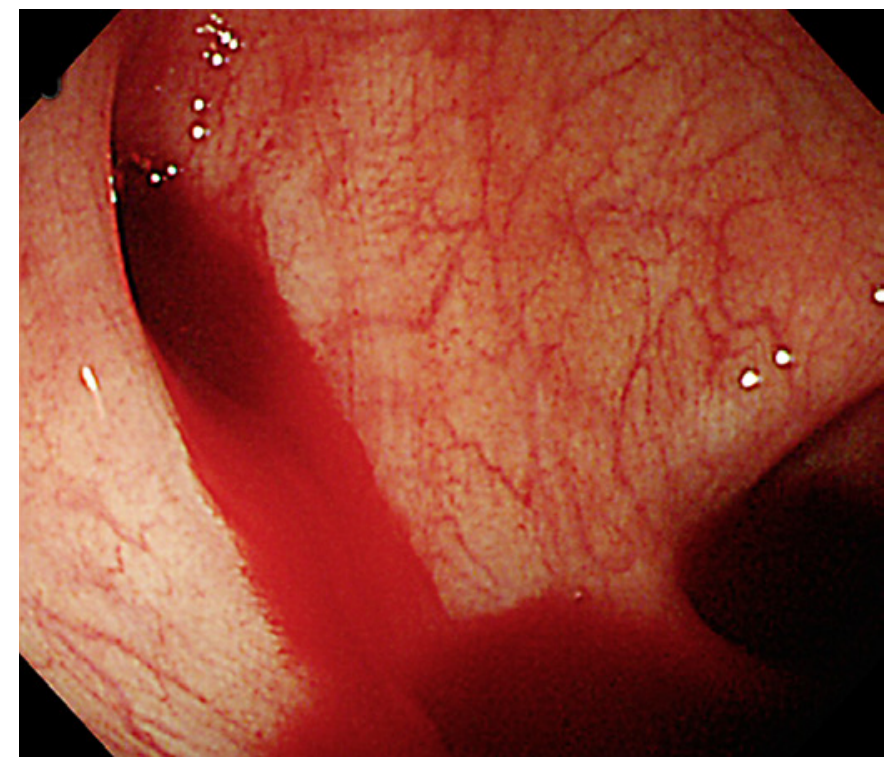

Fig. 2. A 72-year-old Japanese man with diverticular bleeding in the ascending colon. Colonoscopy shows bleeding from the base of a diverticulum.

al. [40] reported, based on the National Inpatient Sample with diverticulitis and colectomy in the United States, that Asian inpatients with diverticulitis were more likely to undergo a right hemicolectomy than were non-Asian inpatients ( 22.7 vs. $4.1 \%$ ) and that there were statistically significant differences in mortality (non-Asian 2.2 vs. Asian 4.2\%) (Table 1). In contrast, Manabe et al. [38] reported that the mortality rate of colonic diverticulitis in 21 Japanese hospitals was significantly higher in patients with complications than in those without complications ( 2.8 vs. $0.2 \%$ ) (Table 1$)$. In Korea, the mortality rate was significantly higher in patients with left-sided colonic diverticular disease than in patients with right-sided colonic diverticular disease (10.8 vs. $0 \%$ ) [37].

\section{Diverticular Bleeding}

Among patients with diverticulosis, diverticular bleeding occurs in approximately $5-15 \%$ and is massive in onethird of patients (Fig. 2) [41]. The prevalence of hospitalizations per 100,000 persons for diverticular bleeding decreased over a 10-year period from 32.5 to 27.1 in the United States [1]. Approximately 15-25\% of adults with uncomplicated diverticula will progress to bleeding [42]. One study found a rate of $3 \%$ in patients with asymptomatic diverticulosis [43], but this was not a cohort study.
Another study reported that the incidence of bleeding was 0.30 per 1,000 patient-years [44], but the diagnosis of asymptomatic and complicated diverticulosis in this study was based on questionnaires, not colonoscopy. Because this bleeding can be massive and recurs frequently in $14-38 \%$ of patients $[43,45]$, it involves repeated examination, hospitalization, and blood transfusion, with a substantial adverse impact on quality of life.

The incidence of diverticular bleeding increases with age, and $46 \%$ of patients were older than 80 years [1]. Both women and men had similar rates of diverticular bleeding; however, diverticular bleeding was decreasing in men compared to women.

Colonic diverticular bleeding occurs on the right side of the colon in $50-90 \%$ of patients with diverticula (Table 1) $[42,46,47]$. This reveals a marked increase in the risk of bleeding for the right-sided diverticula, as in Western countries only $25 \%$ of diverticula are located on the right side of the colon [48]. The prevalence of diverticular bleeding was higher in black persons (34.4 of 100,000 in 2010) than in white persons [1]; therefore, hospitalization for diverticular bleeding was significantly more common in black persons than in white persons. The distribution of the diverticula in the ascending colon or hepatic flexure was higher in blacks than in whites [9].

In Asia, Niikura et al. [5] reported that the cumulative incidence of bleeding from diverticulosis was approximately $2 \%$ in 5 years and $10 \%$ in 10 years and that the overall incidence was 0.46 per 1,000 patient-years. An age of more than 70 years and both-sided diverticulosis increased the risk of bleeding. Nagata et al. [3] reported that diverticular bleeding was found in 427 of 28,192 patients (1.5\%; mean age: 69.7 years) with a higher incidence in men $(66.3 \%)$; the bleeding was predominantly of the both-sided type (47.0\%) (Table 1). The proportion of diverticular bleeding was increasing significantly from $1.02 \%$ ( 22 of 2,157 subjects) in 2003 to $1.67 \%$ ( 69 of 4,159 subjects) in 2011, and it was associated with an increased number of patients aged 40-59 years. Kinjo et al. [49] also reported that patients with colonic diverticular bleeding were older male patients ( $\geq 70$ years old) and that colonic diverticular bleeding was more frequent in the late-period group (2007-2013) than in the early-period group (1995-2006).

Dao et al. [50] reported that the overall mortality rate among a total of 99,415 discharges for diverticular hemorrhage in the National Inpatients Sample in the United States was $1.8 \%$ and that transferred patients had higher in-hospital mortality rates than admitted patients (3.5 vs. $1.8 \%, p<0.001)$. Another study in Western countries re- 
ported that the mortality rate was $1.1-4.1 \%$ (Table 1) [51, 52]. Chen et al. [53] reported that the overall mortality rate in 73 patients with colonic diverticular bleeding in Taiwan was $4.11 \%$. In contrast, Niikura et al. [54] reported, using a national database in Japan, that the in-hospital mortality rate in patients with diverticular bleeding was $0.7 \%(62 / 8,422)$ (Table 1$)$.

\section{Segmental Colitis}

Segmental colitis associated with diverticulosis (SCAD) or diverticular colitis is defined as a type of active chronic inflammation that resembles inflammatory bowel disease. It mostly appears in the sigmoid colon affected by diverticular disease with sparing of the rectum and proximal colon [55-58]. The prevalence of SCAD in patients with diverticulosis ranges from 0.26 to $1.5 \%$ [5658]. The prevalence of SCAD is higher in men, with a mean age of 64 years [58]. However, SCAD has also been reported in younger patients. Only a few cases of SCAD have been reported in Asian countries.

\section{Burden of Diverticular Disease}

Approximately $25 \%$ of patients with acute diverticulitis develop associated acute or chronic complications requiring admissions and operations. Moreover, diverticular disease recurs frequently. Diverticular disease is associated with a significant economic burden in terms of health-care costs and resource utilization [59]. There are more than 2.5 million clinic visits, 330,000 emergency department visits, and 200,000 hospital admissions for diverticular disease without hemorrhage each year in the United States [60]. Delvaux [61] reported that there were almost 800,000 hospital admissions for diverticular disease in European countries. As a countermeasure for the burden of diverticular disease, a systematic review reported that there was no difference in failure rates of medical treatment (6.5 vs. $4.6 \%)$ and recurrence rates (13.0 vs. $12.1 \%$ ) between patients who received ambulatory care and those who received inpatient care for uncomplicated diverticulitis [62]. Ambulatory treatment was associated with daily cost savings of between 600 and 1,900 EUR per patient treated. One study showed that provision of care by an integrated multidisciplinary digestive health service can significantly reduce overall costs $(p=0.0497)$ and the length of hospital stay $(p=0.017)$ in patients admitted for diverticulitis compared to costs for care provided by non- integrated inpatients services [63]. Moreover, a recent systematic review showed that care by gastroenterologists was associated with a significantly shorter length of stay than care provided by general physicians [64].

Recent evidence suggests that delaying elective surgery for patients with recurrent, uncomplicated diverticular disease is the optimal treatment strategy from both an economic perspective and a clinical perspective, as this approach results in a reduced symptom burden, fewer admissions, less additional treatment, lower rates of mortality and colostomy, an increase in quality-adjusted life years, and significant cost savings [65]. In patients for whom surgery is indicated, a recent meta-analysis showed that, compared to open surgery, laparoscopic surgery for diverticular disease was associated with a significantly reduced length of stay and fewer complications [66]. Recently, Bollom et al. [62] reported that the number of emergency department visits due to diverticulitis and associated costs continued to rise between 2006 and 2013, whereas the rate of bowel surgeries and inpatient admissions through the emergency department for diverticulitis has decreased [67].

Diverticular bleeding can be massive and recurs frequently; therefore, it involves repeated examination, hospitalization, and blood transfusion. In Asia, based on the diagnosis procedure combination data, Ito et al. [68] reported that rebleeding and blood transfusion were related to high cost of hospitalization for colonic diverticular bleeding. Assertive endoscopic hemostasis might decrease the cost of hospitalization in patients with colonic diverticular rebleeding.

\section{Conclusion}

Diverticulosis is complicated by diverticulitis, diverticular bleeding, and segmental colitis associated with diverticula, all of which occur frequently. The prevalence of diverticulosis, diverticulitis, and diverticular bleeding in Western countries is different from that in Asian countries. In Western countries, diverticulosis and diverticulitis are predominantly located on the left side of the colon; in contrast, they are predominantly present on the right side in Asian countries. Diverticular bleeding is predominantly located on the right side in Western countries. Both-sided diverticulosis increases the risk of bleeding in Asian countries. The differences in prevalence between Western and Asian countries may be associated with congenital factors, environment, food style, or intestinal microbiota. In the near future, the reasons for the
Imaeda/Hibi 
mechanism of differences in the prevalence of diverticulosis, diverticulitis, and diverticular bleeding between Western and Asian countries are expected to be clarified, and prevention strategies for diverticular disease are expected to be established.

\section{Disclosure Statement}

The authors declare no conflicts of interest.

\section{References}

1 Wheat CL, Strate LL: Trends in hospitalization for diverticulitis and diverticular bleeding in the United States from 2000 to 2010. Clin Gastroenterol Hepatol 2016;14:96-103.

2 Yamamichi N, Shimamoto T, Takahashi Y, Sakaguchi Y, Kakimoto H, Matsuda R, Kataoka Y, Saito I, Tsuji Y, Yakabi S, Takeuchi C, Minatsuki C, Niimi K, Asada-Hirayama I, Nakayama C, Ono S, Kodashima S, Yamaguchi D, Fujishiro M, Yamaji Y, Wada R, Mitsushima T, Koike K: Trend and risk factors of diverticulosis in Japan: age, gender, and lifestyle/metabolic-related factors may cooperatively affect on the colorectal diverticula formation. PLoS One 2015;10:e0123688.

3 Nagata N, Niikura R, Aoki T, Shimbo T, Itoh T, Goda Y, Suda R, Yano H, Akiyama J, Yanase M, Mizokami M, Uemura N: Increase in colonic diverticulosis and diverticular hemorrhage in an aging society: lessons from a 9-year colonoscopic study of 28,192 patients in Japan. Int J Colorectal Dis 2014;29:379385.

4 Acosta JA, Grebenc ML, Doberneck RC, McCarthy JD, Fry DE: Colonic diverticular disease in patients 40 years old or younger. Am Surg 1992;58:605-607.

5 Niikura R, Nagata N, Shimbo T, Aoki T, Yamada A, Hirata Y, Sekine K, Okubo H, Watanabe K, Sakurai T, Yokoi C, Mizokami M, Yanase M, Akiyama J, Koike K, Uemura N: Natural history of bleeding risk in colonic diverticulosis patients: a long-term colonoscopy-based cohort study. Aliment Pharmacol Ther 2015;41:888-889.

6 Hughes LE: Postmortem survey of diverticular disease of the colon. I. Diverticulosis and diverticulitis. Gut 1969;10:336-344.

7 Manousos ON, Truelove SC, Lumsden K: Prevalence of colonic diverticulosis in general population of Oxford area. Br Med J 1967;3: 762-763.

8 Parks TG: Natural history of diverticular disease of the colon. Clin Gastroenterol 1975;4: 53-69.

9 Peery AF, Keku TO, Martin CF, Eluri S, Runge T, Galanko JA, Sandler RS: Distribution and characteristics of colonic diverticula in a United States screening population. Clin Gastroenterol Hepatol 2016;14:980-985.

10 Everhart JE, Ruhl CE: Burden of digestive diseases in the United States part II: lower gastrointestinal diseases. Gastroenterology 2009; 136:741.
11 Golder M, Ster IC, Babu P, Sharma A, Bayat M, Farah A: Demographic determinants of risk, colon distribution and density scores of diverticular disease. World J Gastroenterol 2011;17:1009-1017.

12 Sharara AI, El-Halabi MM, Mansour NM, Malli A, Ghaith OA, Hashash JG, Maasri K, Soweid A, Barada K, Mourad FH, El Zahabi L: Alcohol consumption is a risk factor for colonic diverticulosis. J Clin Gastroenterol 2013;47:420-425.

13 Song JH, Kim YS, Lee JH, Ok KS, Ryu SH, Lee JH, Moon JS: Clinical characteristics of colonic diverticulosis in Korea: a prospective study. Korean J Intern Med 2010;25:140-146.

14 Wang FW, Chuang HY, Tu MS, King TM, Wang JH, Hsu CW, Hsu PI, Chen WC: Prevalence and risk factors of asymptomatic colorectal diverticulosis in Taiwan. BMC Gastroenterol 2015;15:40.

15 Nakada I, Ubukata H, Goto Y, Watanabe Y, Sato S, Tabuchi T, Soma T, Umeda K: Diverticular disease of the colon at a regional general hospital in Japan. Dis Colon Rectum 1995;38:755-759.

16 Nakaji S, Danjo K, Munakata A, Sugawara K, MacAuley D, Kernohan G, Baxter D: Comparison of etiology of right-sided diverticula in Japan with that of left-sided diverticula in the West. Int J Colorectal Dis 2001;17:365373.

17 Miura S, Kodaira S, Shatari T, Nishioka M, Hosoda Y, Hisa TK: Recent trends in diverticulosis of the right colon in Japan: retrospective review in a regional hospital. Dis Colon Rectum 2002;43:1383-1389.

18 Kubo A, Ishiwata J, Maeda Y, Kida T, Yamabe $\mathrm{K}$, Shimosegawa T: Clinical studies on diverticular disease of the colon. Jpn J Med 1983; 22:185-189.

19 Sugihara K, Muto T, Morioka Y, Asano A, Yamamoto T: Diverticular disease of the colon in Japan. A review of 615 cases. Dis Colon Rectum 1984;27:531-537.

20 Stollman NH, Raskin JB: Diagnosis and management of diverticular disease of the colon in adults. Ad Hoc Practice Parameters Committee of the American College of Gastroenterology. Am J Gastroenterol 1999;94:3110-3121.

21 Shahedi K, Fuller G, Bolus R, Cohen E, Vu M, Shah R, Agarwal N, Kaneshiro M, Atia M, Sheen V, Kurzbard N, van Oijen MG, Yen L, Hodgkins P, Erder MH, Spiegel B: Long-term risk of acute diverticulitis among patients with incidental diverticulosis found during colonoscopy. Clin Gastroenterol Hepatol 2013;11:1609-1613.

22 Etzioni DA, Mack TM, Beart RW Jr, Kaiser AM: Diverticulitis in the United States: 19982005: changing patterns of disease and treatment. Ann Surg 2009;249:210-217.

23 Nguyen GC, Sam J, Anand N: Epidemiological trends and geographic variation in hospital admissions for diverticulitis in the United States. World J Gastroenterol 2011;17:16001605.

24 Rodkey GV, Welch CE: Changing patterns in the surgical treatment of diverticular disease. Ann Surg 1984;200:466-478.

25 Rosemar A, Angeras U, Rosengren A: Body mass index and diverticular disease: a 28 -year follow-up study in men. Dis Colon Rectum 2008;51:450-455.

26 Strate LL, Liu YL, Aldoori WH, Syngal S, Giovannucci EL: Obesity increases the risks of diverticulitis and diverticular bleeding. Gastroenterology 2009;136:115-122.

27 Dobbins C, Defontgalland D, Duthie G, Wattchow DA: The relationship of obesity to the complications of diverticular disease. Colorectal Dis 2006;8:37-40.

28 Schauer PR, Ramos R, Ghiatas AA, Sirinek KR: Virulent diverticular disease in young obese men. Am J Surg 1992;164:446-448.

29 Parks TG: Natural history of diverticular disease of the colon. A review of 521 cases. $\mathrm{Br}$ Med J 1969;4:639-642.

30 Bahadursingh AM, Virgo KS, Kaminski DL, Longo WE: Spectrum of disease and outcome of complicated diverticular disease. Am J Surg 2003;186:696-701.

31 Ambrosetti P, Chautems R, Soravia C, PeirisWaser N, Terrier F: Long-term outcome of mesocolic and pelvic diverticular abscesses of the left colon: a prospective study of 73 cases. Dis Colon Rectum 2005;48:787-791.

32 Woods RJ, Lavery IC, Fazio VW, Jagelman DG, Weakley FL: Internal fistulas in diverticular disease. Dis Colon Rectum 1988;31:591596.

33 Nagorney DM, Adson MA, Pemberton JH: Sigmoid diverticulitis with perforation and generalized peritonitis. Dis Colon Rectum 1985;28:71-75.

34 Salem L, Flum DR: Primary anastomosis or Hartmann's procedure for patients with diverticular peritonitis? A systematic review. Dis Colon Rectum 2004;47:1953-1964. 
35 Wong SK, Ho YH, Leong AP, Seow-Choen F: Clinical behavior of complicated right-sided and left-sided diverticulosis. Dis Colon Rectum 1997;40:344-348.

36 Kim JH, Cheon JH, Park S, Kim BC, Lee SK, Kim TI, Kim WH: Relationship between disease location and age, obesity, and complications in Korean patients with acute diverticulitis: a comparison of clinical patterns with those of Western populations. Hepatogastroenterology 2008;55:983-986.

37 Oh HK, Han EC, Ha HK, Choe EK, Moon SH, Ryoo SB, Jeong SY, Park KJ: Surgical management of colonic diverticular disease: discrepancy between right- and left-sided diseases. World J Gastroenterol 2014;20:10115-10120.

38 Manabe N, Haruma K, Nakajima A, Yamada M, Maruyama Y, Gushimiyagi M, Yamamoto $\mathrm{T}$ : Characteristics of colonic diverticulitis and factors associated with complications: a Japanese multicenter, retrospective, cross-sectional study. Dis Colon Rectum 2015;58: 1174-1181.

39 Schneider EB, Singh A, Sung J, Hassid B, Selvarajah S, Fang SH, Efron JE, Lidor AO: Emergency department presentation, admission, and surgical intervention for colonic diverticulitis in the United States. Am J Surg 2015;210:404-407.

40 Choi CS, Koltun WA, Hollenbeak CS: Higher mortality in surgically managed diverticulitis is associated with Asian ethnicity and rightsided disease. Dis Colon Rectum 2016;59: 216-223.

41 Imbembo AL, Bailey RW: Diverticular disease of the colon; in Sabiston DC Jr (ed): Textbook of Surgery, ed 14. Churchill Livingstone, 1992, p 910

42 Gostout CJ, Wang KK, Ahlquist DA, Clain JE, Hughes RW, Larson MV, Petersen BT, Schroeder KW, Tremaine WJ, Viggiano TR, et al: Acute gastrointestinal bleeding. Experience of a specialized management team. J Clin Gastroenterol 1992;14:260-267.

43 McGuire HH Jr, Haynes BW Jr: Massive hemorrhage for diverticulosis of the colon: guidelines for therapy based on bleeding patterns observed in fifty cases. Ann Surg 1972;175: 847-855.

44 Strate LL, Liu YL, Huang ES, Giovannucci EL, Chan AT: Use of aspirin or nonsteroidal antiinflammatory drugs increases risk for diverticulitis and diverticular bleeding. Gastroenterology 2011;140:1427-1433.

45 McGuire HH Jr: Bleeding colonic diverticula. A reappraisal of natural history and management. Ann Surg 1994;220:653-656.
46 Meyers MA, Alonso DR, Gray GF, Baer JW: Pathogenesis of bleeding colonic diverticulosis. Gastroenterology 1976;71:577-583.

47 Casarella WJ, Kanter IE, Seaman WB: Rightsided colonic diverticula as a cause of acute rectal hemorrhage. N Engl J Med 1972;286: 450-453.

48 Rege RV, Nahrwold DL: Diverticular disease. Curr Probl Surg 1989;26:133-189.

49 Kinjo K, Matsui T, Hisabe T, Ishihara H, Maki S, Chuman K, Koga A, Ohtsu K, Takatsu N, Hirai F, Yao K, Washio M: Increase in colonic diverticular hemorrhage and confounding factors. World J Gastrointest Pharmacol Ther 2016;7:440-446.

50 Dao HE, Miller PE, Lee JA, Kermani R, Hackford AW: Transfer status is a risk factor for increased in-hospital mortality in patients with diverticular hemorrhage. Int $J$ Colorectal Dis 2013;28:273-276.

51 Aytac E, Stocchi L, Gorgun E, Ozuner G: Risk of recurrence and long-term outcomes after colonic diverticular bleeding. Int J Colorectal Dis 2014;29:373-378.

52 Poncet G, Heluwaert F, Voirin D, Bonaz B, Faucheron JL: Natural history of acute colonic diverticular bleeding: a prospective study in 133 consecutive patients. Aliment Pharmacol Ther 2010;32:466-471.

53 Chen CY, Wu CC, Jao SW, Pai L, Hsiao CW: Colonic diverticular bleeding with comorbid diseases may need elective colectomy. J Gastrointest Surg 2009;13:516-520.

54 Niikura R, Yasunaga H, Yamaji Y, Horiguchi H, Fushimi K, Yamada A, Hirata Y, Koike K: Factors affecting in-hospital mortality in patients with lower gastrointestinal tract bleeding: a retrospective study using a national database in Japan. J Gastroenterol 2015;50:533540.

55 Lamps LW, Knapple WL: Diverticular disease-associated segmental colitis. Clin Gastroenterol Hepatol 2007;5:27-31.

56 Tursi A, Elisei W, Brandimarte G, Giorgetti GM, Lecca PG, Di Cesare L, Inchingolo CD, Aiello F: The endoscopic spectrum of segmental colitis associated with diverticulosis Colorectal Dis 2010;12:464-470.

57 Imperiali G, Meucci G, Alvisi C, Fasoli R, Ferrara A, Girelli CM, Rocca F, Saibeni S, Minoli G: Segmental colitis associated with diverticula: a prospective study. Gruppo di Studio per le Malattie Infiammatorie Intestinali (GSMII). Am J Gastroenterol 2000;95:10141016.
58 Mann NS, Hoda KK: Segmental colitis associated with diverticulosis: systematic evaluation of 486 cases with meta-analysis. Hepatogastroenterology 2012;59:2119-2121.

59 Reddy VB, Longo WE: The burden of diverticular disease on patients and healthcare systems. Gastroenterol Hepatol (NY) 2013;9: 21-27.

60 Peery AF, Crockett SD, Barritt AS, Dellon ES, Eluri S, Gangarosa LM, Jensen ET, Lund JL, Pasricha S, Runge T, Schmidt M, Shaheen NJ, Sandler RS: Burden of gastrointestinal, liver, and pancreatic diseases in the United States. Gastroenterology 2015;149:1731-1741.

61 Delvaux M: Diverticular disease of the colon in Europe: epidemiology, impact on citizen health and prevention. Aliment Pharmacol Ther 2003;18(suppl 3):71-74.

62 Bollom A, Austrie J, Hirsch W, Nee J, Friedlander D, Ellingson K, Cheng V, Lembo A: Emergency department burden of diverticulitis in the USA, 2006-2013. Dig Dis Sci 2017; 62:2694-2703.

63 Balasubramanian I, Fleming C, Mohan HM, Schmidt K, Haglind E, Winter DC: Out-patient management of mild or uncomplicated diverticulitis: a systematic review. Dig Surg 2017;34:151-160.

64 Arseneau KO, Yeaton P, Kahaleh M, Cominelli F: Effect of digestive health care services integration on resource use and outcomes in patients with digestive disorders. Clin Gastroenterol Hepatol 2003;1:145-151.

65 Provenzale D, Ofman J, Gralnek I, Rabeneck L, Koff R, McCrory D: Gastroenterologist specialist care and care provided by generalists - an evaluation of effectiveness and efficiency. Am J Gastroenterol 2003;98:21-28.

66 Richards RJ, Hammitt JK: Timing of prophylactic surgery in prevention of diverticulitis recurrence: a cost-effectiveness analysis. Dig Dis Sci 2002;47:1903-1908.

67 Purkayastha S, Constantinides VA, Tekkis PP, Athanasiou T, Aziz O, Tilney H, Darzi AW, Heriot AG: Laparoscopic vs. open surgery for diverticular disease: a meta-analysis of nonrandomized studies. Dis Colon Rectum 2006;49:446-463.

68 Ito Y, Sakata Y, Yoshida H, Nonaka S, Fujii S, Tanaka Y, Shirai S, Takeshita E, Akutagawa T, Kawakubo H, Yamamoto K, Tsuruoka N, Shimoda R, Iwakiri R, Fujimoto K: High cost of hospitalization for colonic diverticular bleeding depended on repeated bleeding and blood transfusion: analysis with diagnosis procedure combination data in Japan. Digestion 2017;96:76-80. 